\title{
Marine Policy Special Issue: SDG synergies for sustainable fisheries and poverty alleviation
}

\author{
Daniela Diza ${ }^{\mathrm{a}}$ Elisa Morgeraa ${ }^{\mathrm{a}}$, Meriwether Wilson ${ }^{\mathrm{b}}$ \\ aUniversity of Strathclyde, School of Law, United Kingdom \\ bUniversity of Edinburgh, School of Geosciences, United Kingdom
}

\begin{abstract}
This special issue contributes to ongoing discussions of SDG 14 with a special focus on its relationship with other SDGs and broader international policy and legal instruments towards a more holistic and effective interpretation and implementation of this ocean-focused Goal. The emphasis in the 2030 Agenda for Sustainable Development on the role of oceans and coasts for sustainable development, including with respect to poverty reduction, food security, nutrition, well-being and traditional livelihoods, thus offers an ideal opportunity to push the boundaries of scientific, policy and legal reflection forward towards an integrated implementation of the SDGs and the achievement of the three pillars of sustainable development.
\end{abstract}

Marine biodiversity and associated ecosystem services related to ecological productivity and resilience continue to decline globally ${ }^{1}$ due to increasing anthropogenic pressures such as overfishing, habitat destruction, pollution, climate change and ocean acidification. The importance of marine conservation and sustainable use of its resources has been recognised as a central component of sustainable development as it contributes to poverty alleviation, food security, sustainable livelihoods. ${ }^{2}$ This notion was reinstated by the adoption of a stand-alone Sustainable Development Goal (SDG) on the conservation and sustainable use of oceans, seas and marine resources for sustainable development (SDG 14) as part of the UN 2030 Agenda for Sustainable Development.

To maintain and restore ocean health, productivity and resilience, SDG 14 encompasses ten targets focused on science-based ecosystem protection and sustainable management of marine and coastal ecosystems. These aim to avoid or minimise the anthropogenic pressures highlighted above, as well as underpin fisheries subsidies reform, access rights for small-scale fisheries, enhanced scientific cooperation and monitoring, capacity building and technology transfer.

This special issue ${ }^{3}$ contributes to ongoing discussions of SDG 14 with a special focus on its relationship with other SDGs and broader international policy and legal instruments towards a more holistic and effective interpretation and implementation of this ocean-focused Goal. The emphasis in the 2030 Agenda for Sustainable Development on the role of oceans and coasts for sustainable development, including with respect to poverty reduction, food security, nutrition, well-being and traditional livelihoods, thus offers an ideal opportunity to push the boundaries of scientific, policy and legal reflection forward towards an integrated implementation of the SDGs and the achievement of the three pillars of sustainable development. 
This Issue is particularly timely in light of the recent UN Ocean Conference on SDG 14 that took place in June 2017 at the UN headquarters in New York and culminated with, inter alia, the adoption of an intergovernmental declaration entitled Our Ocean Our Future: Call for Action. ${ }^{4}$ This Call for Action contains a number of elements that add conceptual clarity to the interpretation of SDG 14 targets by including reference to terms and instruments not previously incorporated into SDG 14. For instance, while 'ecosystem services' language has not been included in any SDG 14 target, in the Call for Action, several marine ecosystem services are highlighted. The document also expressly recognises the oceans as an important source of biodiversity and ecosystem services for the planet as a whole. ${ }^{5}$ As part of the Ecosystem Services for Poverty Alleviation programme, this special issue therefore analyses connections and tensions between the ecosystem approach, in particular the ecosystem approach to fisheries, marine ecosystem service multiple dimensions of poverty across different SGD 14 targets and in the relationships between SDG 14 and other Goals.

Another conceptual contribution of the Call for Action was the emphasis on the indivisible and integrated nature of the different SDGs. ${ }^{6}$ More specifically it called on all stakeholders to "approach the implementation of Goal 14 in an integrated and coordinated way and promote policies and actions that take into account the critical inter-linkages among the targets of Goal 14, [and] the potential synergies between Goal 14 and the other Goals (...)". In this respect, the article by Singh et al. set in this issue sets the scene by mapping synergies and trade-offs across the 17 SDGs and their 169 targets. The article by Ntona and Morgera then proposes an integrative framework for the SDGs implementation through the implementation of marine spatial planning.

In addition, the Call for Action further calls for the application of the ecosystem approach in the context of area-based management tools. ${ }^{7}$ This is another significant conceptual clarification as the term "ecosystem approach" was not incorporated into SDG 14, as opposed to the explicit reference contained in the 2012 UN Conference on Sustainable Development (or Rio+20) outcome document. ${ }^{8}$ It is important to note, however, that the application of the ecosystem approach has been more recently incorporated as an indicator for SDG 14.2 on sustainable management and protection of marine and coastal ecosystems in order to avoid significant adverse impacts and taking action for their restoration for a healthy and productive ocean. Given the increasing impact of the ecosystem approach in international policy and legal frameworks, ${ }^{9}$ the article by Kenny et al. in this issue explores the latest scientific findings and best practices concerning the ecosystem approach to fisheries that could be replicated and adapted when implementing SDG 14.2 and 14.4 also in connection to other relevant Goals such as SDG 2 (on food security) and SDG 1 (on eliminating poverty).

Universality was also a central element during the negotiations of the SDGs. The article by Brooker et al. in this issue explores this notion by addressing challenges and opportunities regarding small-scale fishing and sustainable livelihoods from a developed country's perspective, with a case study from Scotland concerning the commercial fishing industry. Universality also comes to mind when thinking of fiscal instruments that promote the conservation and the sustainable use of living marine resources. The article by Mohammed, Steinbach and Steele in this issue thus addresses SDG 14.6 on fisheries subsidies and 14.B on small-scale fisheries access to marine resources from a broader perspective of fiscal reform for sustainable fisheries.

To ensure their effectiveness, the SDGs should be implemented in concert with other relevant policy and legal instruments, including the UN Convention on the Law of the Sea (UNCLOS) and the Convention on Biological Diversity (CBD). In this connection, parties to the CBD in late 2016 called for mainstreaming the CBD's Aichi Biodiversity Targets $^{10}$ into the implementation of the SDGs ${ }^{11}, 11$ as well as integrating biodiversity and ecosystem services into the fisheries sector, including as part of the ecosystem approach. ${ }^{12}$ This is particularly important in the context of SDG 14 given that the 
timeframes for implementation of most targets on both sides were set in 2020. In addressing the synergies between the SDGs and the CBD in this regard, the article by Rees et al. in this issue discusses the need for incorporating Aichi Biodiversity Target 11 (taking into account its qualified language) into SDG 14.5 on marine protected areas. The article by Diz et al., in turn, assesses the role of CBD's 'other effective area-based conservation measures' in implementing SDG 14.5 in connection to other Goals such as SDG 2 on food security and SDG 1 on poverty elimination, while achieving healthier, more productive and resilient ecosystems (SDG 14.2). The article by Wilson et al. explores the challenges and opportunities of Small Island Developing States (SDG 14.7, and more broadly Large Ocean States) in relation to ecosystem-based adaptation and restoration for the achievement of multiple SDGs towards achieving both marine biodiversity and climate adaptation resilience.

In closing the Special Issue, the article by Morgera and Ntona reflects on multi-scalar considerations related to the SDGs, focusing on inter-State obligations related to technology transfer (SDG 14.a) as means for a holistic implementation of SDG 14 and their local implications in the context of small-scale fisheries. Overall, the Special Issue aims to contribute to a more systematic and in-depth scholarly and policy debate on actual and potential SDG synergies that can support the operationalisation of SDG 14 in a comprehensive, integrated, universal and holistic manner. In doing so, it calls attention to the challenges and opportunities at different levels and in different processes to work towards healthy, productive and resilient oceans and respective ecosystem services and governance systems, which enable sustainable and resilient livelihoods and the alleviation of poverty in its multiple dimensions.

\section{Acknowledgements}

D Diz, E Morgera and M Wilson would like to gratefully acknowledge the important contribution of the Marine Benefits project Advisory Board and partners, ${ }^{13}$ and the funding received from the Ecosystem Services for Poverty Alleviation (ESPA) programme - - a global interdisciplinary research programme funded by the United Kingdom's Department for International Development ( DFID ), the Natural Environment Research Council (NERC) and the Economic and Social Research Council (ESRC), as part of the UK's Living with Environmental Change partnership. Project n. NE/M007650/1 - Sharing the benefits of sustainable fisheries: from global to local legal approaches to marine ecosystem services for poverty alleviation (Marine Benefits Project Benefits project). The guest editors are particularly grateful to Mara Ntona for her invaluable contribution to this Special Issue and to the Marine Benefits project.

\footnotetext{
${ }^{1}$ Secretariat of the Convention on Biological Diversity (2014) Global Biodiversity Outlook 4. Montréal, 155 pp.

2 The Future We Want, UN General Assembly (UNGA) Resolution 66/288 (2012), Annex, para. 158. See also 1992 Agenda 21, chapter 17 (on the protection of the oceans, all kinds of seas, including enclosed and semienclosed seas, and coastal areas and the protection, rational use and development of their living resources), which has previously introduced this notion.

${ }^{3}$ This Special Issue is part of an inter-disciplinary project, titled "Sharing the benefits of sustainable fisheries: from global to local legal approaches to marine ecosystem services for poverty alleviation" (or Marine Benefits project n. NE/M007650/1), which explores whether and how the legal tool "fair and equitable benefitsharing," as part of the ecosystem approach, can be integrated with the concept of marine ecosystem services to reduce the systemic poverty of coastal marine societies who depend upon marine resources for both food security and income generation. This project was funded through the Ecosystem Services for Poverty
} 
Alleviation (ESPA) programme - a global interdisciplinary research programme funded by the United Kingdom's Department for International Development (DFID), the Natural Environment Research Council (NERC) and the Economic and Social Research Council (ESRC), as part of the UK's Living with Environmental Change partnership

${ }^{4}$ Call for Action, UN Doc A/CONF.230/1

${ }^{5}$ Call for Action (A/Conf.230/11), para. 3.

${ }^{6}$ Call for Action (A/Conf.230/11), paras. 6 and 13 (a)

${ }^{7}$ Call for Action, para 13 (j). Paragraph 8 on the need for an integrated, interdisciplinary and cross-sectoral approach indirectly reflects key elements of the ecosystem approach.

${ }^{8}$ The Future We Want, UNGA Resolution 66/288 (2012), Annex para. 158. It is important to note, however, that application of the ecosystem approach has been more recently incorporated as an indicator for SDG 14.2 on sustainable management and protection of marine and coastal ecosystems in order to avoid significant adverse impacts and taking action for their restoration for a healthy and productive ocean.

${ }^{9} \mathrm{D}$ Diz, Fisheries management in areas beyond national jurisdiction: the impact of ecosystem based lawmaking. Vol. 13. Martinus Nijhoff Publishers, 2013; E Morgera, "The ecosystem approach and the precautionary principle" in E Morgera and J Razzaque (Eds) Biodiversity and Nature Protection Law (Edward Elgar, 2017).

${ }^{10}$ CBD Decision $\mathrm{X} / 2$.

${ }^{11}$ As per CBD Decision XIII/3, para. 14.

${ }^{12}$ As per CBD Decision XIII/3, paras. 59-76.

${ }^{13}$ Marine Benefits project, Advisory Board and partners, online: http://www.marinebenefits.ed.ac.uk/advisory_boa 